\title{
Comparing Nigella sativa Oil and Fish Oil in Treatment of Vitiligo
}

\author{
Alireza Ghorbanibirgani ${ }^{1, "}$; Ali Khalili ${ }^{1}$; Darioush Rokhafrooz ${ }^{2}$ \\ ${ }_{1}^{1}$ Faculty Member of Nursing, Department of Nursing and Midwifery, Gachsaran Branch, Islamic Azad University, Gachsaran, IR Iran \\ ${ }^{2}$ Shahid Beheshti University of Medical Sciences, Tehran, IR Iran \\ ${ }^{*}$ Corresponding Author: Alireza Ghorbanibirgani, Faculty Member of Nursing, Department of Nursing and Midwifery, Gachsaran Branch, Islamic Azad University, Gachsaran, IR Iran. \\ Tel:+98-9163032478, Fax:+98-6112245868, E-mail:Alenc5@gmail.com
}

\section{Received: February 16, 2012; Revised: February 18, 2014; Accepted: April 28, 2014}

\begin{abstract}
Background: Vitiligo is one of the autoimmune skin diseases that destroy the melanocytes of the skin. Moreover, its prevalence varies in different countries and regions.

Objectives: The aim of this study was to compare the effect of Nigella sativa and fish oil on vitiligo lesions of the patients referred to a dermatology clinic.

Materials and Methods: This randomized, double blind clinical trial was conducted in the dermatology clinic of the Imam Khomeini Hospital Ahvaz, Iran, from June to December 2011. We used a randomized simple sampling. From 96 patients with vitiligo, 52 eligible patients were selected and allocated to two groups with equal size. The study medications were applied twice a day by patients on their lesions. After six months, the improvement rate of lesions was assessed by the Vitiligo Area Scoring Index (VASI). Data were analyzed using SPSS v. $15 ;$ P value $<0.05$ was considered as statistically significant.

Results: After six months, a mean score of VASI decreased from 4.98 to 3.75 in patients applying topical Nigella sativa and from 4.98 to 4.62 in those using topical fish oil. Most of the percent improvement observed in upper extremities, trunk, head, and neck of those who received Nigella sativa and head, neck, trunk, and feet of those who received fish oil. No adverse effect was reported by the patients.

Conclusions: Nigella sativa oil and fish oil were effective in reduction the size of patient's lesions; however, Nigella sativa was more effective in comparison to the fish oil. Therefore, using Nigella sativa with the major drugs in the treatment of vitiligo is recommended.
\end{abstract}

Keywords:Nigella sativa; Fish Oils; Vitiligo

\section{Background}

Vitiligo is a skin disease that causes white spots due to loss of skin pigment cells. In vitiligo, melanocytes (cells that produce pigment) of the skin, mucous membrane, and the retina are damaged that causes white spots in different areas of skin (1). This disease is the most common disorder of the skin pigmentation with an incidence rate of $0.1 \%$ to $2 \%$ in different populations (2-4). The symptoms of the disorder manifest before the age of 20 in about half of the patients. Approximately, one-fifth of the family members of the patients are affected by vitiligo. The disease affect all races and genders equally (1) and is more common in people with other autoimmune disorders (3). This disease is more likely to develop in late childhood (9-12 years old) through middle age (1). Vitiligo lesions usually create milky and white spots that are usually seen symmetrically and bilaterally. The most commonly affected areas of the skin include the face, lips, hands, arms, feet, and the genitals. Moreover, the color of the hairs that grow in the affected areas is usually white (2). Although the main cause of this disorder is not known yet, possible mechanisms such as genetic, autoimmune, biochemical, nervous, and viral factors are proposed as probable causes (1-3). Many studies concerning vitiligo and its treatment have been conducted; however, no unique effective treatment that may improve all patients has been identified yet. Topical treatments are preferred in patients with vitiligo. The use of herbal medications is among the effective treatments that has had useful effects in treating vitiligo lesion. In this context, different studies have been conducted on various herbal medications worldwide to control as well as to treat vitiligo. Among the herbal medications, Ginkgo biloba (5, 6), Nigella sativa (Black cumin) (7-9), and black pepper (10) can be noted. They have been used in several studies and had different effects on patients with vitiligo. Caraway plant (Carum carvi) is widely used to treat various diseases in the Asian and European countries. Thymoquinone is a major component of the seeds of this plant, i.e. Nigella sativa, that has anti-inflammatory, antimicrobial, antioxidant, and antitumor effects as well as the strengthening effects on the immune system; in fact, the presence of $\alpha$-linolenic acid (ALA) and stearidonic acid (SDA) enhances the immune response, especially in T cells (11-19). This medication is used to treat kidney disease $(20,21)$,

Implication for health policy/practice/research/medical education: Is effective and desirable for improving and treating skin lesions.

Copyright (c) 2014, Iranian Red Crescent Medical Journal; Published by Kowsar Corp. This is an open-access article distributed under the terms of the Creative Commons Attribution License, which permits unrestricted use, distribution, and reproduction in any medium, provided the original work is properly cited. 
high blood pressure (22-24), rheumatoid arthritis (25), diabetes mellitus (26-28), allergic rhinitis (29), asthma $(30,31)$, and osteoporosis (32). Fish oil is also a rich source of omega-3 fatty acids including eicosapentaenoic acid (EPA) and docosahexaenoic acid (DHA), which are among the essential fatty acids. In the human body, EPA and DHA are converted to a series of active chemical compounds called eicosanoids that have anti-inflammatory properties. Another advantage of fish oil is related to its vitamin $\mathrm{E}$ component. Vitamin $\mathrm{E}$ is a potent antioxidant that helps to protect cells against free radical damage. It also helps to process of fatty acids and to improve the health of the hair and skin (33-38); moreover, it is used in the treatment of various diseases (39-41).

\section{Objectives}

This randomized, double blind, controlled clinical trial was conducted to compare the effect of Nigella sativa oil with fish oil on improvement of the vitiligo lesions.

\section{Materials and Methods}

Patients with vitiligo referred to the dermatology clinic of Imam Khomeini Hospital, Ahvaz, Iran, from June to December 2011 were assessed. Randomization was performed by using a simple random table. A total of 96 patients were examined by a dermatologist. We included patients with generalized or localized vitiligo for less than five years. The patients' disease was confirmed by a dermatologist. Exclusion criteria included positive family history of vitiligo, pregnancy (in women), and allergy to Nigella sativa and/ or fish oil. Finally, 52 patients were recruited after signing a written informed consent form. They were randomly allocated to two 26-patient groups. Nigella sativa seeds were purchased from the local herbalist in Ahvaz. The seeds were authenticated by Pharmacognosy Department, School of Pharmacy, Isfahan University of Medical Sciences, Iran. Seeds were cleaned, dried, mechanically smashed and powdered, extracted with $96 \%$ ethanol, and evaporated with rotary evaporator to render the extract alcohol-free. The extracts were transferred into tubes, each containing $100 \mathrm{~g}$ of Nigella sativa. The above procedures were undertaken in the Giah Essence Phytopharm Co, Gorgan, Iran. Thus, Nigella sativa oil and fish oil were prepared in quite similar containers (100 g container) by a pharmacologist at pharmacy. The A (Nigella sativa oil) group applied Nigella sativa oil to the areas of skin lesions and the B (Fish oil) group received fish oil twice a day for six months. Seven visit sessions were made for the patients entering the study by one observer: one before the study and the rest at the end of each month through the sixth month of treatment. During the study, the participants and the researcher were unaware of the drug in tubes. A form was prepared for each patient in which the data were recorded. During the treatment period, skin lesions of patients were evaluated by observers using Vitiligo Area Scoring Index (VASI) tool. The percentage of vitiligo involvement was calculated in terms of hand units. One hand unit, which encompasses the palm plus the volar surface of all digits, is approximately equivalent to $1 \%$ of the total body surface area. The degree of pigmentation was estimated at the nearest of the one of the following: $100 \%$, complete depigmentation, i.e. no pigment is present (score $=5$ ); $75 \%$, depigmented area exceeded the pigmented area (score $=4) ; 50 \%$, pigmented and depigmented areas were equal (score $=3$ ); $25 \%$, pigmented area exceeded depigmented area (score $=2$ ); $10 \%$, only specks of depigmentation were present (score $=1$ ); and no depigmentation (score $=0$ ). Patients were assessed for percentage of pigmentation at the time of entering to the study, as well as at the end of each month during study by VASI (minimum score of $0=$ no depigmentation; and maximum score of $5=$ no pigmentation).

The validity and reliability of VASI have been reported previously (42-45). In order to gain reliability of VASI in this study, test-retest method with one month interval was used in which 15 patients from each group were asked to record the intensity, size, and quantity of depigmentation. The correlation coefficient was calculated to be $89 \%$. Necessary warnings such as avoiding the use of the medications in the wounded areas, preventing drug exposure to the eyes, and washing the hands with water after application of the drug were given to the patients. The patients were also asked to inform the researcher if any side effects were noticed. To comply with the ethical issues, the study was conducted on the patients in coordination with physicians treating the patients and approval of the Ethics Committee of Gachsaran Azad University (ethical code B-52/324-011, date 14/04/2011). After getting permission from the Ethics Committee, the interested patients were invited to participate in this study by providing information for them about the medications and the goals of the study. Furthermore, patients were allowed to withdraw the study at any time they were not willing to continue working with the team. The data obtained from the study were used in order to assess the skin lesions intensity changes between two groups by using of descriptive statistical methods (percent, frequency, and mean \pm standard deviation). Repeated measurement of ANOVA test was used in the cases of having normal distribution and otherwise, Friedman test was used. In this study, we used SPSS v.15 (SPSS Inc., Chicago, Illinois, USA) and Pvalue $<0.05$ was considered as statistically significant in all tests.

\section{Results}

After six months of treatment, all patients in both groups completed the study without attrition. Data from all the 52 patients, 19 (40\%) female and 33 (60\%) male, were analyzed. The mean age of participants was $43.65 \pm 3.21$ years, with 41 \pm 4.62 years in men and $47 \pm 2.18$ years in women. The mean age at the onset of disease was $4.11 \pm 1.46$ years. Thirty nine patients (75\%) were categorized as the generalized and 13 (25\%) patients as localized type of vitiligo. After six months, 
the mean VASI score decreased from $4.98 \pm 4.81$ to $3.75 \pm 3.91$ in the Nigella sativa oil group (Table 1), and from $4.98 \pm 4.80$ to $4.62 \pm 4.36$ in the fish oil group (Table 2 ). The correlation coefficient ( $r$ ) of Nigella sativa and fish oil effects in two study groups is presented in Table 3 . The highest percentage of improvement in the Nigella sativa oil group was observed in the lower extremities, trunk, head, and neck; and in the fish oil group in the head and neck, trunk, and feet. The lowest percentage of improvement in the Nigella sativa oil group was observed in the head, neck, and hands; and in the fish oil group in the hands and lower extremities. No specific side effects were reported by patients during six months of treatment.

In a pilot study on 10 patients, sample size was calculated according to the following formula by two mean comparison $(\alpha=0.05$ and $\beta=0.2)$ as 52 and the patients were screened consecutively.

$$
\mathrm{n}=\left(\mathrm{Z}_{(1-\beta)}+\mathrm{Z}_{(1-\alpha / 2)}\right)^{2}\left(\delta_{1}^{2}+\delta_{2}^{2}\right) /\left(\mu_{1}-\mu_{2}\right)^{2}
$$

Repeated measures of ANOVA test indicated that there was no significant difference between reduction of VASI score in Nigella sativa oil and fish oil groups from the first through the third month of the study; however, there were significant differences in reducing VASI score in favor of Nigella sativa oil from the fourth through the sixth month ( $\mathrm{P}<0.020$; Figure 1$)$.

There was no significant difference between reductions of VASI score in Nigella sativa with fish oil groups during the first through the third month of the study; however, after the fourth month, there were significant differences in reduction of VASI score in favor of Nigella sativa.

Table 1. Vitiligo Area Scoring Index Scores in Nigella sativa Group a,b

\begin{tabular}{|c|c|c|}
\hline \multirow[t]{2}{*}{ Weeks of Treatment } & Nigella sativa Oil & \multirow[t]{2}{*}{ P Value } \\
\hline & VASI Score (Mean \pm SD) & \\
\hline Before Treatment & $4.98 \pm 4.81$ & 0.094 \\
\hline First Month & $4.96 \pm 4.75$ & 0.092 \\
\hline Second Month & $4.85 \pm 4.63$ & 0.084 \\
\hline Third Month & $4.77 \pm 4.51$ & 0.080 \\
\hline Fourth Month & $4.41 \pm 4.28$ & 0.048 \\
\hline Fifth Month & $4.07 \pm 4.11$ & 0.034 \\
\hline Sixth Month & $3.75 \pm 3.91$ & 0.020 \\
\hline \multicolumn{3}{|c|}{$\begin{array}{l}\mathrm{a} \text { Abbreviation: VASI, vitiligo area scoring index. } \\
\mathrm{b} \text { There was no significant difference in reductions of VASI score } \\
\text { between Nigella sativa and fish oil from the first through the third } \\
\text { month of the study; however, there were significant differences in } \\
\text { reduction of VASI score in favor of Nigella sativa after the fourth month } \\
(\mathrm{P}<0.020) \text {. }\end{array}$} \\
\hline
\end{tabular}

\section{Discussion}

Vitiligo is an annoying and frustrating skin disease. It even affects the patients' confidence and quality of life. Although various drugs are prescribed for these patients, no single drug that can reduce symptoms and skin lesions has been discovered. The most effective available drugs are herbal medications, which at least might have no side effect in comparison to chemical drugs and the patient can use them without fear of disturbing side effects.

This study was performed in order to compare the effect of Nigella sativa oil and fish oil on improving vitiligo lesions. Skin lesions of the patients were measured in

\begin{tabular}{|c|c|c|}
\hline \multirow[t]{2}{*}{ Weeks of Treatment } & Fish Oil & P Value \\
\hline & VASI Score $($ Mean \pm SD $)$ & - \\
\hline Before Treatment & $4.98 \pm 4.80$ & 0.093 \\
\hline First Month & $4.97 \pm 4.78$ & 0.091 \\
\hline Second Month & $4.90 \pm 4.72$ & 0.079 \\
\hline Third Month & $4.83 \pm 4.59$ & 0.081 \\
\hline Fourth Month & $4.74 \pm 4.54$ & 0.078 \\
\hline Fifth Month & $4.69 \pm 4.43$ & 0.075 \\
\hline Sixth Month & $4.62 \pm 4.36$ & 0.067 \\
\hline
\end{tabular}

a Abbreviation: VASI, vitiligo area scoring index.

$\mathrm{b}$ There was no significant difference between reduction of VASI score in fish oil group from the first through sixth month of the study $(\mathrm{P}<$ 0.067)

Table 3. Correlation Between Nigella sativa and Fish Oil With Improvement of Vitiligo Lesions

\begin{tabular}{lcc}
\hline- & Nigella sativa Group & Fish Oil Group \\
\hline $\begin{array}{l}\text { Correlation } \\
\text { Coefficient }(\mathbf{r})\end{array}$ & 0.864 & -0.489 \\
P Value & 0.020 & 0.067 \\
\hline
\end{tabular}

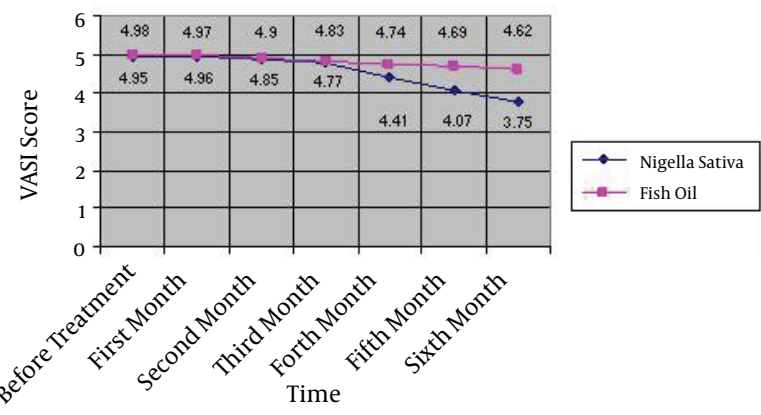

Figure 1. Reduction of VASI Score in Nigella sativa and Fish Oil Groups During the Six Months of Study 
determined times. After applying topical Nigella sativa oil and fish oil for six months, the total VASI score showed a significant improvement from baseline through the end of the study. The use of these drugs might reduce the size of lesions in patients and both drugs showed a downward trend in the VASI score from baseline to end of treatment (Figure 1). By searching databases such as PubMed, no similar study was found in this regard and our study seems to be the first study concerning treatment of vitiligo disease in humans by Nigella sativa. The latest study, which was done on animals in 2011 on the efficacy of Nigella sativa extract on animals, shows that applying drug on a lizard caused an increase in pigmentation and led to a darkening of the animal skin (8). In the present study, the depigmented areas were reduced over time and the skin color showed improvement. One reason for this positive response to treatment is the thymoquinone component of Nigella sativa. Thymoquinone, the main constituent of Nigella sativa seeds, protects cells against oxidative damage induced by a variety of free radical-generating pathologies (46). Thymoquinone can simulate the activity of acetylcholine, which causes the release of melanin and darkening of the skin through stimulation of cholinergic receptors (8). In addition, Nigella sativa oil administration was tolerable as well as safe and improved oxidative stress and clinical condition of patients (47). Fish oil could also make a good improvement by reducing the lesions size within six months although this recovery was less significant than that of Nigella sativa. In a study that was performed on 39 patients with chronic psoriasis in Birjand, the fish oil had the same effect in reducing skin lesions size in comparison to a combination of salicylic acid and betamethasone (40). The positive effect of fish oil on skin diseases such as vitiligo was indicated in another study in India (48). One reason that fish oil affects the skin diseases is the presence of omega-3 fatty acids that can prevent drying and scaling of skin in eczema, acne, and other skin diseases. In addition, it accelerates the recovery from skin diseases. Moreover, fish oil led to synthesis of anti-inflammatory properties in the skin as the result of EPA and DHA found in the phospholipid membrane. In the current study, administration of Nigella sativa and fish oil significantly decreased skin lesions size, indicating an improvement in clinical condition. A previous study has shown similar effects of Nigella sativa administration to an animal (8). The strong point of the present study is that it was performed in Iran for the first time and hypothesized that a combined method (Nigella sativa and fish oil) could be effective and desirable for improving and treating skin lesions. It was also shown that this type of treatment has no significant side effects and resulted in high patient satisfaction and acceptance. It is necessary to conduct long-time researches with larger sample size and different medication doses in order to confirm current findings. There were limitations to our study; for instance, this study was conducted in one clinic that might not be the representative of all the patients and hence, the results could not be generalized. Furthermore, some of the factors influencing skin lesions such as nutrition were uncontrollable. In summary, considering the distinct effect of fish oil and Nigella sativa oil on symptoms of patients with vitiligo, it is recommended to use herbal medications in treating these patients, especially since they have no significant side effects.

\section{Acknowledgements}

This research received no specific grant from any funding agency in the public, commercial, or profit sectors.

\section{Authors' Contribution}

Alireza Ghorbanibirgani wrote the primary draft and performed sampling; Ali Khalili and Darioush Rokhafrooz helped in preparing the manuscript.

\section{References}

1. Burns T, Breathnach S, Cox N, Griffiths C. Rook's Textbook ofDermatology: Oxford. Blackwell Science; 2010. pp. 164-6.

2. James WD, Elston DM, Berger TG, Andrews GC. Andrews' diseases of the skin: Clinical dermatology.Philadelphia: Saunders Elsevier; 2011. pp. 115-6.

3. Bolognia JL, Jorizzo JL, Rapini R. Dermatology.Philadelphia: Mosby Elsevier; 2008. p. 214.

4. Yaghoobi R, Omidian M, Bagherani N. Vitiligo: a review of the published work.J Dermatol. 2011;38(5):419-31.

5. Ghorbani Birgani A, Masoodi R. Epidemiological study of vitiligo on referred patients from Imam Khomeini Hospital, Ahvaz, Iran, 2009-2012. Jundishapur J Chronic Disease Care. 2013;2(3):57-62.

6. Szczurko O, Shear N, Taddio A, Boon H. Ginkgo biloba for the treatment of vitilgo vulgaris: an open label pilot clinical trial. BMC Complement Altern Med. 2011;11:21.

7. Szczurko O, Boon HS. A systematic review of natural health product treatment for vitiligo. BMC Dermatol. 2008;8:2.

8. Ali SA, Meitei KV. Nigella sativa seed extract and its bioactive compound thymoquinone: the new melanogens causing hyperpigmentation in the wall lizard melanophores. J Pharm Pharmacol. 2011;63(5):741-6.

9. Sarkhail P, Esmaily H, Baghaei A, Shafiee A, Abdollahi M, Khademi Y, et al. Burn healing potential of Nigella sativa seed oil in rats. Int JPharmaceutical Sci Res. 2011;2(1):34-40.

10. Ali BH, Blunden G. Pharmacological and toxicological properties of Nigella sativa. Phytother Res. 2003;17(4):299-305.

11. Vinod KR, Santhosha D, Anbazhagan S. Formulation and Evaluation of Piperine Creama New Herbal Dimensional Approach for Vitiligo Patioents. Int J Pharm and Pharm Sci. 2011;3(2):29-33.

12. Salomi MI, Nair SC, Panikkar KR. Inhibitory effects of Nigella sativa and saffron (Crocus sativus) on chemical carcinogenesis in mice. Nutr Cancer. 1991;16(1):67-72.

13. Salomi NJ, Nair SC, Jayawardhanan KK, Varghese CD, Panikkar KR. Antitumour principles from Nigella sativa seeds. Cancer Lett. 1992;63(1):41-6.

14. Worthen DR, Ghosheh OA, Crooks PA. The in vitro anti-tumor activity of some crude and purified components of blackseed, Nigella sativa L. Anticancer Res. 1998;18(3A):1527-32.

15. Nagi MN, Mansour MA. Protective effect of thymoquinone against doxorubicin-induced cardiotoxicity in rats: a possible mechanism of protection. Pharmacol Res. 2000;41(3):283-9.

16. Alemi M, Sabouni F, Sanjarian F, Haghbeen K, Ansari S. Anti-inflammatory effect of seeds and callus of Nigella sativa L. extracts on mix glial cells with regard to their thymoquinone content. AAPS PharmSciTech. 2013;14(1):160-7.

17. Ghannadi A, Hajhashemi V, Jafarabadi H. An investigation of the analgesic and anti-inflammatory effects of Nigella sativa seed 
polyphenols. J Med Food. 2005;8(4):488-93.

18. Hosseini M, Zakeri S, Khoshdast S, Yousefian FT, Rastegar M, Vafaee F, et al. The effects of Nigella sativa hydro-alcoholic extract and thymoquinone on lipopolysaccharide - induced depression like behavior in rats. J Pharm Bioallied Sci. 2012;4(3):219-25.

19. Randhawa MA, Alghamdi MS. Anticancer activity of Nigella sativa (black seed) - a review. Am J Chin Med. 2011;39(6):1075-91.

20. Hadjzadeh MA, Khoei A, Hadjzadeh Z, Parizady M. Ethanolic extract of nigella sativa $\mathrm{L}$ seeds on ethylene glycol-induced kidney calculi in rats. Urol J. 2007;4(2):86-90.

21. Yildiz F, Coban S, Terzi A, Savas M, Bitiren M, Celik H, et al. Protective effects of Nigella sativa against ischemia-reperfusion injury of kidneys. Ren Fail. 2010;32(1):126-31.

22. Qidwai W, Hamza HB, Qureshi R, Gilani A. Effectiveness, safety, and tolerability of powdered Nigella sativa (kalonji) seed in capsules on serum lipid levels, blood sugar, blood pressure, and body weight in adults: results of a randomized, double-blind controlled trial.J Altern Complement Med. 2009;15(6):639-44.

23. Leong XF, Rais Mustafa M, Jaarin K. Nigella sativa and Its Protective Role in Oxidative Stress and Hypertension. Evid Based Complement Alternat Med. 2013;2013:120732.

24. Dehkordi FR, Kamkhah AF. Antihypertensive effect of Nigella sativa seed extract in patients with mild hypertension. Fundam Clin Pharmacol. 2008;22(4):447-52.

25. Gheita TA, Kenawy SA. Effectiveness of Nigella sativa oil in the management of rheumatoid arthritis patients: a placebo controlled study. Phytother Res. 2012;26(8):1246-8.

26. Keyhanmanesh R, Bagban H, Nazemiyeh H, Mirzaei Bavil F, Alipour MR, Ahmady M. The Relaxant Effects of Different Methanolic Fractions of Nigella sativa on Guinea Pig Tracheal Chains. Iran JBasic Med Sci. 2013;16(2):123-8.

27. Bamosa AO, Kaatabi H, Lebdaa FM, Elq AM, Al-Sultanb A. Effect of Nigella sativa seeds on the glycemic control of patients with type 2 diabetes mellitus. Indian J Physiol Pharmacol. 2010;54(4):344-54.

28. Boskabady MH, Keyhanmanesh R, Khameneh S, Doostdar Y, Khakzad MR. Potential immunomodulation effect of the extract of Nigella sativa on ovalbumin sensitized guinea pigs. J Zhejiang Univ Sci B. 2011;12(3):201-9.

29. Isik H, Cevikbas A, Gurer US, Kiran B, Uresin Y, Rayaman P, et al. Potential adjuvant effects of Nigella sativa seeds to improve specific immunotherapy in allergic rhinitis patients. Med Princ Pract. 2010;19(3):206-11.

30. Boskabady MH, Mohsenpoor N, Takaloo L. Antiasthmatic effect of Nigella sativa in airways of asthmatic patients. Phytomedicine. 2010;17(10):707-13.

31. Boskabady MH, Javan H, Sajady M, Rakhshandeh H. The possible prophylactic effect of Nigella sativa seed extract in asthmatic patients. Fundam Clin Pharmacol. 2007;21(5):559-66.

32. Seif AA. Nigella Sativa reverses osteoporosis in ovariectomized rats. BMC Complement Altern Med. 2014;14:22.
33. Terkelsen LH, Eskild-Jensen A, Kjeldsen H, Barker JH, Hjortdal VE. Topical application of cod liver oil ointment accelerates wound healing: an experimental study in wounds in the ears of hairless mice. Scand J Plast Reconstr Surg Hand Surg. 2000;34(1):15-20.

34. Wolters M. Diet and psoriasis: experimental data and clinical evidence. BrJ Dermatol. 2005;153(4):706-14.

35. Damsgaard CT, Lauritzen L, Kjaer TM, Holm PM, Fruekilde MB, Michaelsen KF, et al. Fish oil supplementation modulates immune function in healthy infants. J Nutr. 2007;137(4):1031-6.

36. Weitz D, Weintraub H, Fisher E, Schwartzbard AZ. Fish oil for the treatment of cardiovascular disease. Cardiol Rev. 2010;18(5):258-63.

37. Ries A, Trottenberg P, Elsner F, Stiel S, Haugen D, Kaasa S, et al. A systematic review on the role of fish oil for the treatment of cachexia in advanced cancer: an EPCRC cachexia guidelines project. Palliat Med. 2012;26(4):294-304.

38. Arshad A, Al-Leswas D, Stephenson J, Metcalfe M, Dennison A. Potential applications of fish oils rich in n-3 fatty acids in the palliative treatment of advanced pancreatic cancer. Br J Nutr. 2011;106(6):795-800.

39. Jans LA, Giltay EJ, Van der Does AJ. The efficacy of n-3 fatty acids DHA and EPA (fish oil) for perinatal depression. Br J Nutr. 2010;104(11):1577-85.

40. Shahian Madar R, Ghaderi F. Comparison of acid salisylic $2 \%$ and betamethasone with topical fish oil in recovery of psoriasis signs. J Qazvin Univ Med Sci. 2004;8(2):3-7.

41. Simopoulos AP. Omega-3 fatty acids in inflammation and autoimmune diseases. J Am Coll Nutr. 2002;21(6):495-505.

42. Hamzavi I, Jain H, McLean D, Shapiro J, Zeng H, Lui H. Parametric modeling of narrowband UV-B phototherapy for vitiligo using a novel quantitative tool: the Vitiligo Area Scoring Index. Arch Dermatol. 2004;140(6):677-83.

43. Taieb A, Picardo M, Vetf Members . The definition and assessment of vitiligo: a consensus report of the Vitiligo European Task Force. Pigment Cell Res. 2007;20(1):27-35.

44. Bhor U, Pande S. Scoring systems in dermatology. Indian J Dermatol Venereol Leprol. 2006;72(4):315-21.

45. Kawakami T, Hashimoto T. Disease severity indexes and treatment evaluation criteria in vitiligo. Dermatol Res Pract. 2011;2011:750342.

46. Abdel-Moneim A, Morsy BM, Mahmoud AM, Abo-Seif MA, Zanaty MI. Beneficial therapeutic effects of Nigella sativa and/or Zingiber officinale in HCV patients in Egypt. Experimental Clin Sci International online J. 2013;12:943-55.

47. Barakat EM, El Wakeel LM, Hagag RS. Effects of Nigella sativa on outcome of hepatitis C in Egypt. World J Gastroenterol. 2013;19(16):2529-36.

48. Kaimal S, Thappa DM. Diet in dermatology: revisited. Indian J Dermatol Venereol Leprol. 2010;76(2):103-15. 